\title{
Article \\ Influence of the Diatomite Specie on the Peak and Residual Shear Strength of the Fine-Grained Soil
}

\author{
Carlos J. Slebi-Acevedo ${ }^{1}$, Daniel A. Zuluaga-Astudillo ${ }^{2}$, Juan C. Ruge ${ }^{3(D)}$ and Daniel Castro-Fresno ${ }^{1, *(1)}$ \\ 1 GITECO Research Group, Universidad de Cantabria, 39005 Santander, Spain; slebicj@unican.es \\ 2 Escuela de Ingenieros Militares, Ejército de Colombia, Bogotá 111211, Colombia; daniel.zuluaga@esing.edu.co \\ 3 Facultad de Ingeniería, Universidad Militar Nueva Granada, Bogotá 1101111, Colombia; \\ juan.ruge@unimilitar.edu.co \\ * Correspondence: castrod@unican.es
}

Citation: Slebi-Acevedo, C.J.; Zuluaga-Astudillo, D.A.; Ruge, J.C.; Castro-Fresno, D. Influence of the Diatomite Specie on the Peak and Residual Shear Strength of the Fine-Grained Soil. Appl. Sci. 2021, 11, 1352. https://doi.org/10.3390/ app11041352

Received: 18 November 2020

Accepted: 28 January 2021

Published: 3 February 2021

Publisher's Note: MDPI stays neutral with regard to jurisdictional claims in published maps and institutional affiliations.

Copyright: (c) 2021 by the authors. Licensee MDPI, Basel, Switzerland. This article is an open access article distributed under the terms and conditions of the Creative Commons Attribution (CC BY) license (https:// creativecommons.org/licenses/by/ $4.0 /)$.

\begin{abstract}
Diatomite is a powdering mineral mainly composed of diatom microfossils present in marine and lacustrine soils, which influences their physical and mechanical properties. Although many articles have been found in the literature concerning the influence of diatomite in the overall behavior of natural soils, few research efforts have been carried out to evaluate the influence of the diatom microfossil species on their shear resistance. Therefore, in this research, the influence of the diatomite species and the content in the peak and the residual shear strength of diatomite-fine grained soil mixtures was analyzed using the annular shear strength test. Scanning electron microscopy (SEM) and Atterberg limits were also carried out as additional tests to explain the interlocking effect between the microfossils and the soil. Overall, both diatomite species increased both peak and residual shear strength of the soil similar to dense sands. Nevertheless, the Mexican species reveal higher friction angle values compared with Colombian species.
\end{abstract}

Keywords: annular shear strength test; residual; diatomite; kaolin; diatom; marine soil

\section{Introduction}

The soil constitutes the support of many infrastructures such as buildings, bridges, highways, and dams, among others; therefore, understanding the various elements that are part of it seems to be an interest topic in the recent years. Due to the heterogeneity of the soil, the shape of distinct particles conditions some properties, including volumetric properties, permeability, suction, compressibility, shear strength, and cyclic loading [1-3]. Diatoms are unicellular photosynthetic algae which have a skeleton denoted as frustule composed mostly of silica. These microorganisms whose size can vary from 20 to 200 microns have become fossilized through the geological ages, becoming an inherent part of the soil and changing its properties [4-6]. Diatomaceous earth, or diatomite as it is known in the scientific literature [7], are the fossilized diatoms which have settled in seas and lakes (periods near 40 million years) forming marine and lacustrine soil deposits in many parts of the world, such as Mexico City, Bogotá, the capital of Colombia, Osaka Bay in Japan, California in the US, seabed sediments in the Antarctic, Yunnan in China, and the Indian Ocean [8-11]. Given its morphology of hollow structure, the diatomite has a high porosity which helps it to retain a high amount of water. Other characteristics found in the literature are that they present a rough and abrasive surface, low density, large surface area, and absorbent capacity $[12,13]$. These singular characteristics govern the behavior of some soil deposits, leading to an increment in the void ratio and Atterberg limits but also increasing the friction angle, controverting the fundamentals established in the classic mechanical of soils.

Previous studies have been carried out to analyze the influence of the diatomite in the geotechnical properties of fine-grained soils [7]. Díaz-Rodriguez [9] studied the influence of diatomite on geotechnical properties of soils manufacturing artificial mixes of diatom 
microfossils and kaolin. Atterberg limits and shear strength in undrained conditions were performed in soil specimens normally and over-consolidated. Based on the author's conclusion, Atterberg limits increased with the diatom content as well as the friction angle. Similar results were found by Shiwakoti et al. [14], who prepared remolded specimens of soil with diatomite. According to the authors, they conclude that the presence of these microfossils alters the index properties and increases the compressibility as well as the friction angle of the soil. An explanation of this phenomenon could be attributed to the hollow structures of the diatoms and the rough surface which helps to increase the interlocking among the particles.

Exploratory studies have also been carried out in lacustrine soils with presence of diatoms. Caicedo et al. [10] developed an experimental plan in diatomaceous soils located in Bogotá, where more than 2400 tests were performed. Based on their analysis, they concluded that high values of Atterberg limits and friction angle disagree between the classification system based on Atterberg limits and the classification system based on grain size [10]. Although some studies have examined the influence of the diatomite in a standard soil at different dosages [15], a gap was found in studying the influence of a specific species in the geotechnical behavior of the soil. No research efforts have been found in analyzing the type of diatomite in the shear strength properties of the soil. Accordingly, the main aim of this research was to study the presence of two species of diatom microfossils on the shear strength properties of soils. The shear resistance of the soil was determined by the friction angle and the interlocking phenomenon which exists between the particles [16]. Most research focuses on measuring the friction angle at the peak shear strength because, in the majority of geotechnical problems (e.g., foundations), the strains are small and the stresses are below the peak. However, it is better to consider the residual shear strength as parameter design [17]. Therefore, in the current research, the mechanical response of the soil samples was analyzed through the ring shear equipment, whose main advantage is the evaluation of shear strength in both peak and residual conditions.

\section{Materials and Methods}

\subsection{Materials Characterization and Experimental Designs}

In this research, an untreated commercial kaolin available in Bogota (Colombia) with a specific gravity (GS) of 2.69 was employed as the fine-grained soil matrix, and two distinct types of diatom microfossils commonly used as pesticide in the field of agriculture were selected to be studied. The first type of diatom microfossil corresponds to the Alucoseira Granulata species (GS $=2.55$ ), extracted from the lacustrine soil of Tunja in Colombia (Colombian diatomite species), and the second is the Cosconodiscus Centralis (GS = 2.34) imported directly from Mexico City in Mexico (Mexican diatomite species). Scanning electron micrographs (SEM) were taken of the three materials, as shown in Figure 1. According to the SEM images, the kaolin presents a set of many laminar layers overlapping together and without pores within the internal structure. Concerning diatom microfossils, the Colombian species has a cylindrical shape with pores along its walls. Similarly, the Mexican species has a shape of discs with pores, too, along its surface. In both cases, the pores sizes range from 200 to $900 \mathrm{~nm}$, approximately.

Since the particle size is less than $0.075 \mathrm{~mm}$ remaining in the fine range, the particle size distribution for the three materials was obtained through the hydrometer, as ian be seen in Figure 2. From the graph, it can be observed that the three materials fit in the size of the silt. Similar gradation curve was also noticed between Colombian species and kaolin with a more regular size distribution, while in the Mexican species, the slope of the curve is steeper. 

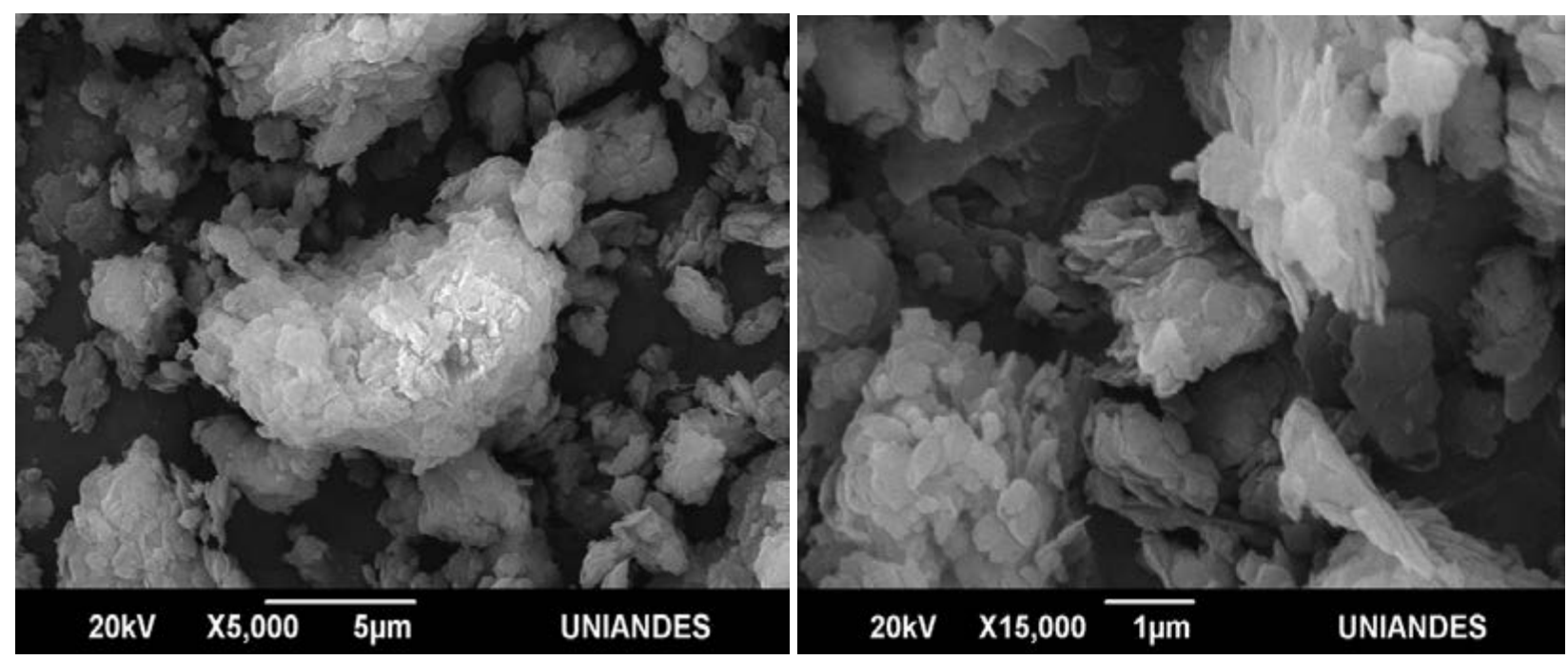

(a)
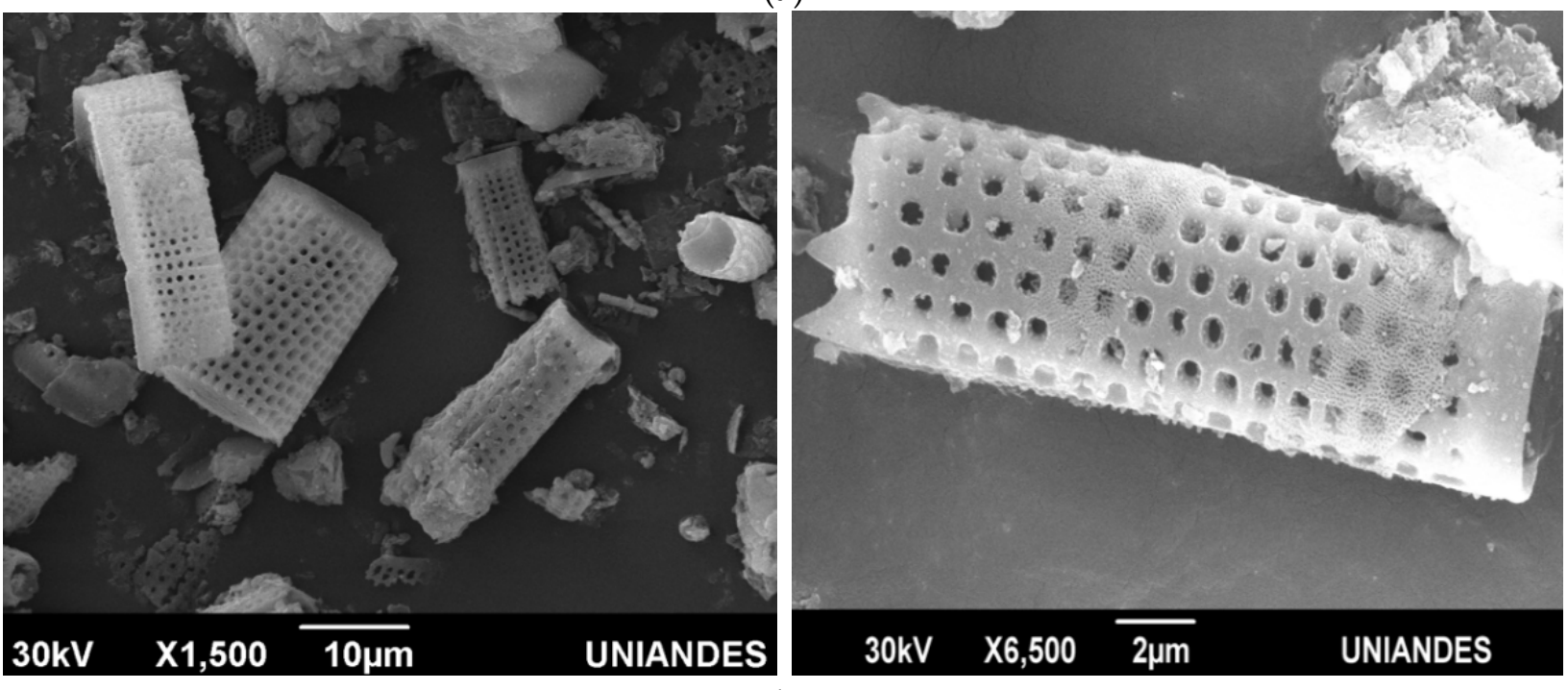

(b)
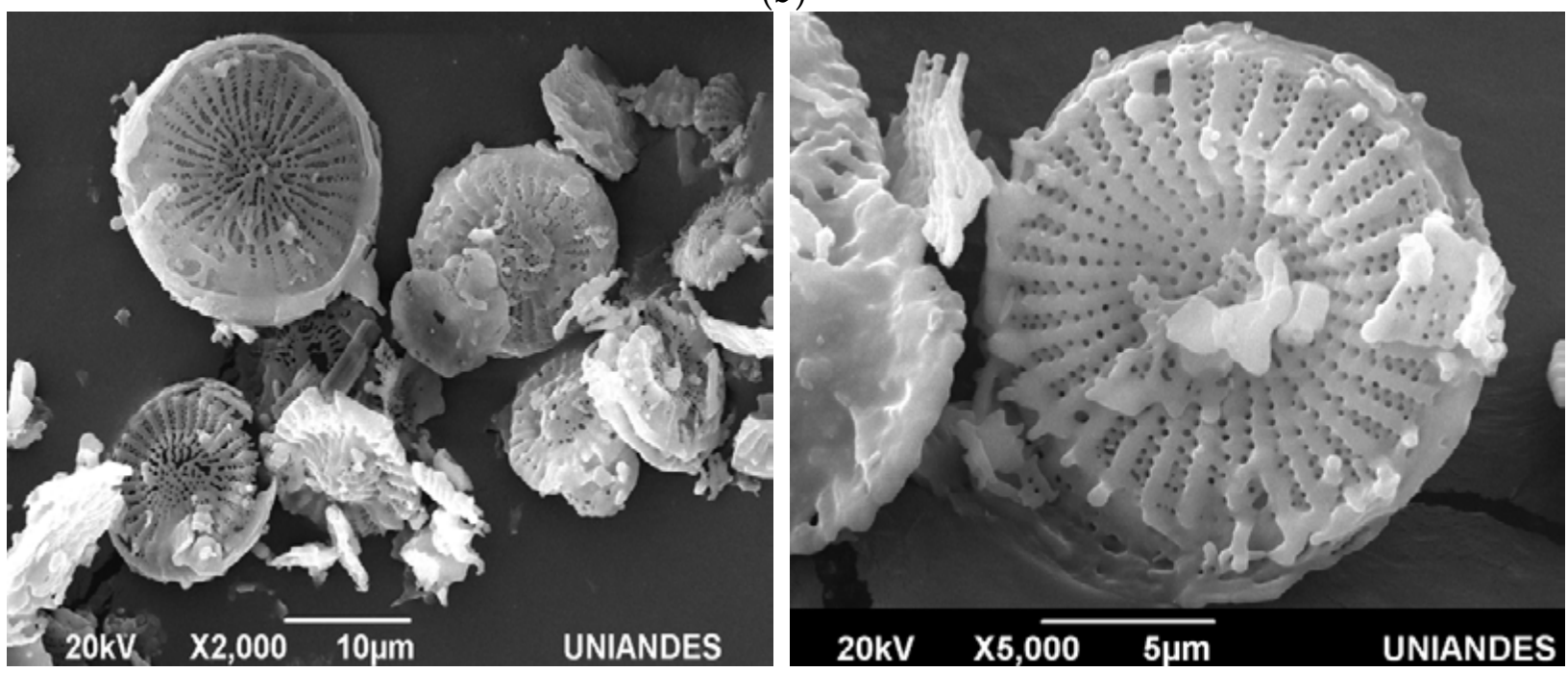

Figure 1. SEM images of: (a) kaolin; (b) Colombian diatom species; (c) Mexican diatom species. 


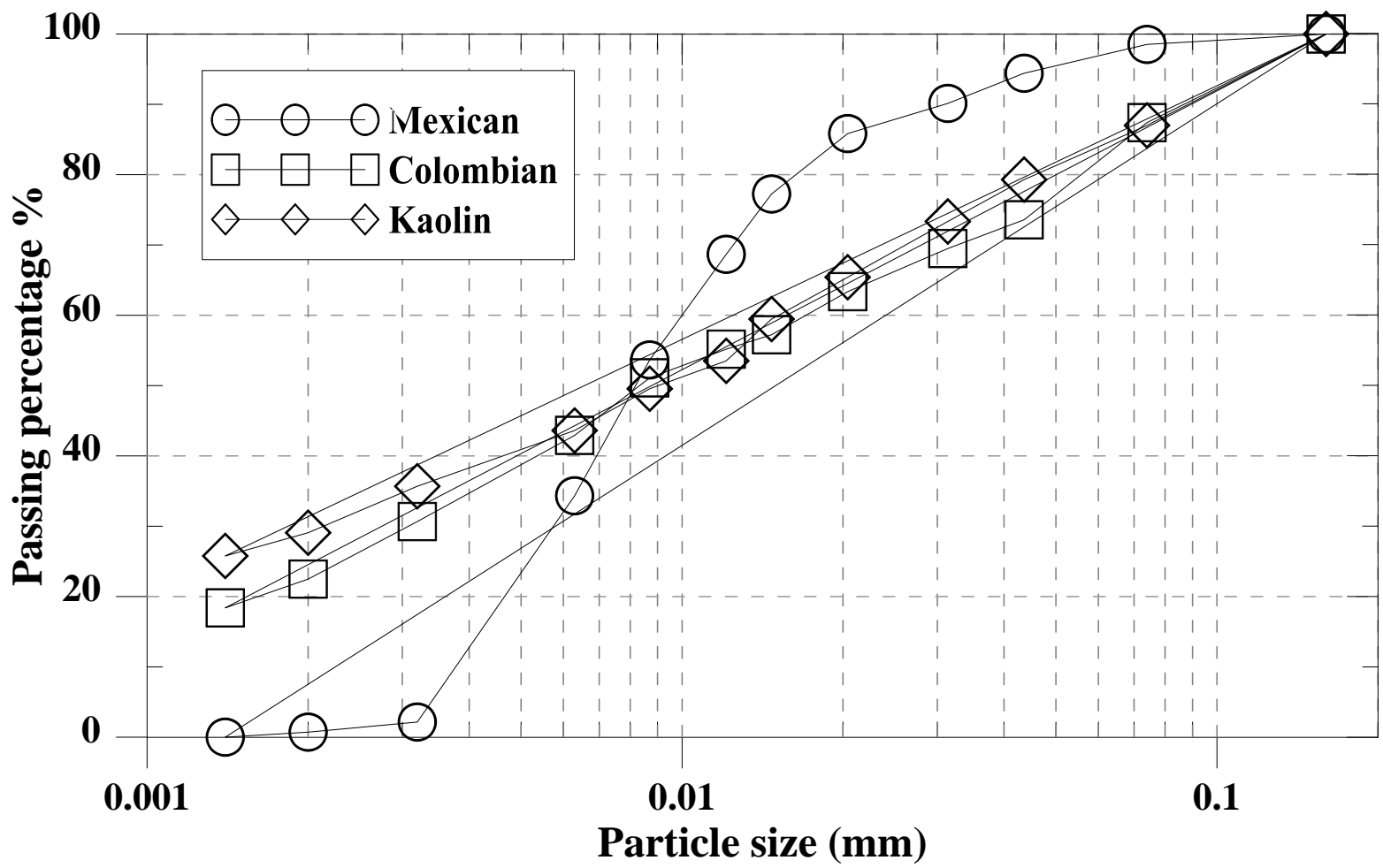

Figure 2. Particle size distribution.

For the experimental designs, artificial mixtures of kaolin and the two diatom microfossils were manufactured to investigate the influence of the diatomite species in the shear strength of the soil. The mass ratio expressed in percentage for all the mixture designs is depicted in Table 1. For the specimen's conditioning before the annular shear strength test, the diatomite-kaolin mixtures were initially blended in dry conditions and then were added to distilled water so that the mixture reached the moisture content corresponding to the liquid limit $(L L)$. Later, the mixes were homogenized and kept wrapped in plastic bags for $24 \mathrm{~h}$ so that all the mixtures were completely humidified.

Table 1. Mass ratio in percentage of the mixture designs.

\begin{tabular}{|c|c|c|c|c|}
\hline Sample $\mathbf{N}^{\circ}$ & Id Mixture & Composition & Liquid Limit & Plastic Limit \\
\hline 1 & Kaolin $100 \%$ & $100 \%$ kaolin & 44 & 24 \\
\hline 2 & Col. Diatomite $20 \%$ & $80 \%$ Kaolin-20\% Colombian diatomite & 50 & 28 \\
\hline 3 & Col. Diatomite $40 \%$ & $60 \%$ Kaolin- $40 \%$ Colombian diatomite & 56 & 32 \\
\hline 4 & Col. Diatomite $60 \%$ & $40 \%$ Kaolin- $60 \%$ Colombian diatomite & 70 & 38 \\
\hline 5 & Col. Diatomite $80 \%$ & $20 \%$ Kaolin- $80 \%$ Colombian diatomite & 83 & 42 \\
\hline 6 & Col. Diatomite $100 \%$ & $100 \%$ Colombian diatomite & 99 & 48 \\
\hline 7 & Mex. Diatomite $20 \%$ & $80 \%$ Kaolin-20\% Mexican diatomite & 49 & 28 \\
\hline 8 & Mex. Diatomite $40 \%$ & $60 \%$ Kaolin- $40 \%$ Mexican diatomite & 56 & 34 \\
\hline 9 & Mex. Diatomite $60 \%$ & $40 \%$ Kaolin- $60 \%$ Mexican diatomite & 80 & 45 \\
\hline 10 & Mex. Diatomite $80 \%$ & $20 \%$ Kaolin- $80 \%$ Mexican diatomite & 110 & 50 \\
\hline 11 & Mex. Diatomite $100 \%$ & $100 \%$ Mexican diatomite & 132 & 60 \\
\hline
\end{tabular}

\subsection{Annular Shear Strength Test}

The annular-or the ring shear strength test, as it is also commonly known-was employed in the current study to measure peak and residual strength of the diatomitekaolin mixtures. It is worth pointing out that estimating the peak and the residual strength is extremely important to find out the limit states of a material or a geotechnical structure, due to the fact that they present different levels of strains and stress paths. For instance, 
in terms of design, an excavation supported by a retaining structure could present two situations. On the one hand, the soil subjected to a passive condition could reveal small strains reaching its peak resistance. On the other hand, the soil mass supported by the retaining structure could already be subjected to large strains and, therefore, be closer to its residual strength.

To perform the test, the reconstituted humidified diatomite-kaolin specimen was removed from the plastic bag and placed in the annular shear cell. The annular shear cell consisted of two concentric rings confined vertically and totally filled with water. Then, normal stress was applied to the sample by the top plate by means of a lever-arm (see Figure 3). Similar to the consolidation test, the samples were consolidated by performing the water pore pressure. Once the mixture was consolidated, the shear strength was measured. To shear the sample, the upper lid and the bottom ring must rotate relative to each other. In that sense, the bottom ring rotated at a controlled angular speed whereas the upper part was restrained by a horizontal beam, and a torque cell device helped to measure the shear resistance of the soil. Both the normal stresses applied on the lever arm and the measured shear stress were previously calibrated to avoid measurement errors. To obtain drained conditions of the test, this was carried out at an angular speed of 0.032 radians per second. The normal stresses to which the samples were consolidated were 100, 200 , and $400 \mathrm{kPa}$, respectively. The vertical displacement was also recorded to analyze the specimen volume change. More details of the procedure are described in the United States Bureau of Reclamation USBR 5730.

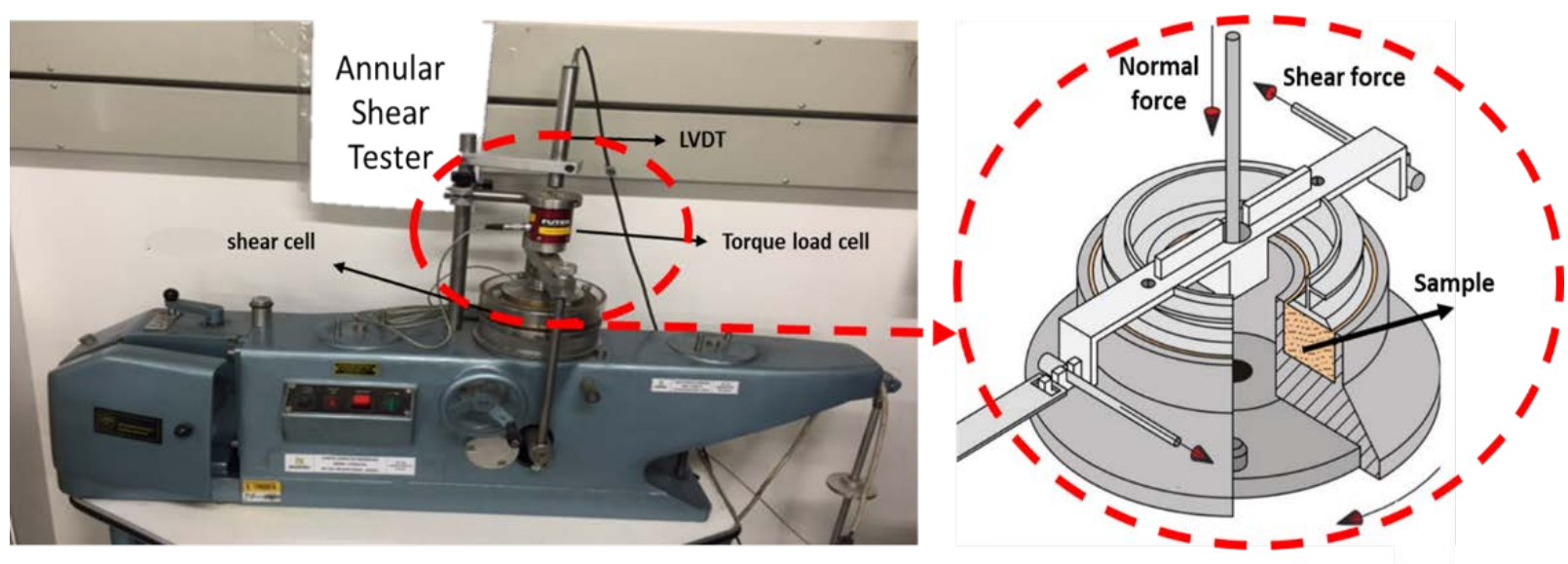

Figure 3. Annular shear strength test. Adapted from [18].

\section{Results and Discussion}

Initially, to have more comprehensible knowledge with respect to the diatomite-kaolin mixtures, the Atterberg limits for the different diatomite concentrations were recorded, as shown in Figure 4. Although it is very typical to obtain the $L L$ of the samples by applying the Casagrande's method, in this research, the fall-cone method was adopted since the calculations for Mexican species was not possible with the conventional method. As can be seen in the Figure 4, the trend suggests that the higher the diatom content was, the higher was the increase in liquid and plastic limit. This result ties well with previous studies wherein limit and plastic limits increase with the increase in diatomite content [9]. An explanation of the above could be that the hollow structure and the pores along their surfaces help to retain more water, increasing their Atterberg limit values. Concerning the type of diatom species, the Mexican displayed higher values of both liquid and plastic limits in relation to Colombian species. In agreement with the above, the Mexican species displayed a lower specific gravity than the Colombian species, indicating that this species could present higher porosity and, as a result, retain more water inside its structure. 


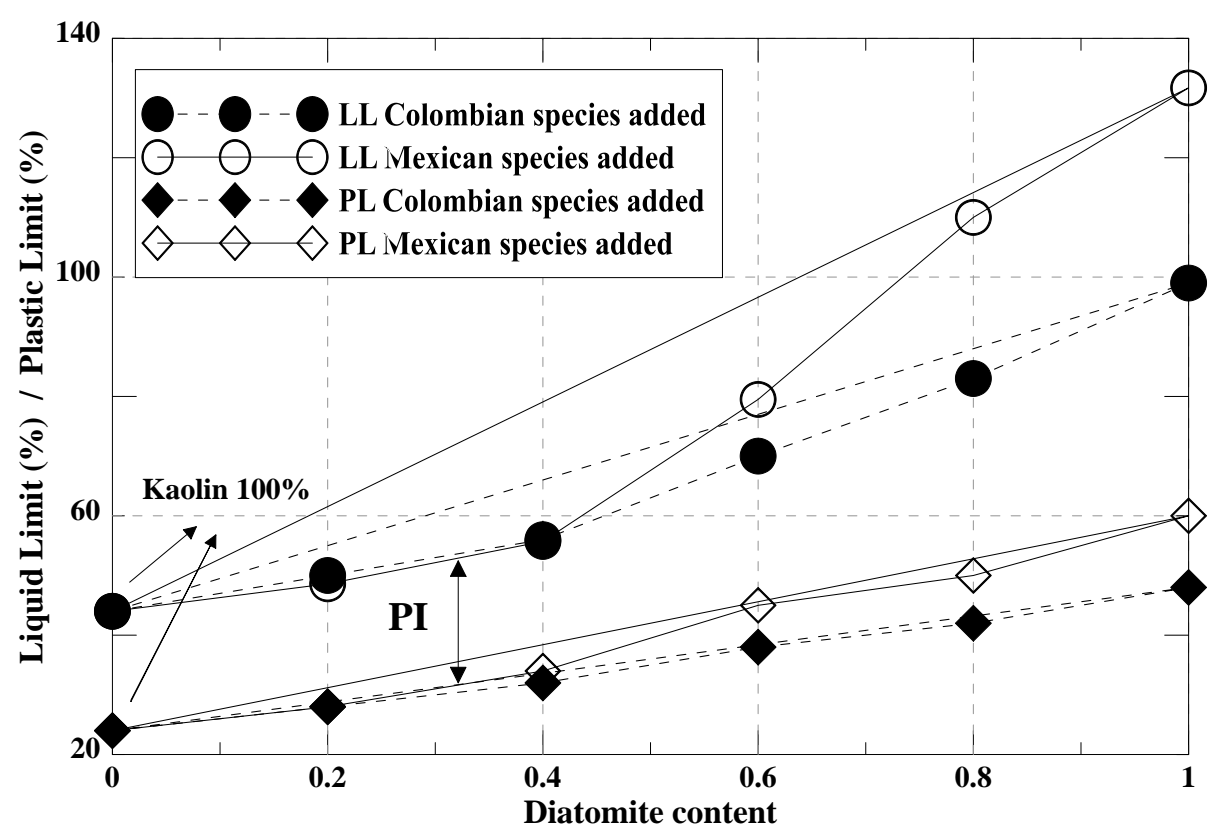

Figure 4. Liquid limit (LL) and plastic limit (PL).

Concerning the shear resistance, the annular shear test presents a particular advantage over other kinds of shear tests (e.g., direct shear) considering the possibility to evaluate the residual strength parameters in the same fail surface and in the same shear stress direction because of the radial movement of the soil container. The residual shear strength is a property of fine soils which evaluates the gradual loss of shear strength along a developed failure surface and, thus, in some cases, it is better to use this value rather than peak shear strength for design purposes. For all diatomite-kaolin mixtures, the shear-strength vs. displacement curves at the three normal stresses were calculated.

Figure 5 shows the results of shear strength vs. displacement for the two diatomite species under study. The increase of diatomaceous material in the mixtures with kaolin revealed slight increases in resistance. Regarding the stress-strain response, it is noted that the shear stress increased in those specimens subjected to greater consolidation steps. Besides, at higher normal stresses, the behavior of the curves looked more typical of a compacted sand than of a normally consolidated clay, especially with higher contents of Mexican diatomite. Unlike clays, the fossilized diatoms did not present electrochemical properties; thus, the improvement in the shear stress could be attributed to the friction produced between the particles. The above is because the higher the diatomite content was, the greater the shear resistance was. With some exceptions, the residual shear stress was kept constant after reaching $4 \mathrm{~mm}$ of horizontal displacement.

A point of interest worth highlighting is that, for all the samples, regardless of the stress level and the amount of diatomite added, they adequately reached the critical state of the soil during the residual condition of the material. This concept is fundamental to understand the response of the soil that has been previously remolded, as it was in the current case, where the specimens underwent a previous peak resistance $[19,20]$. 


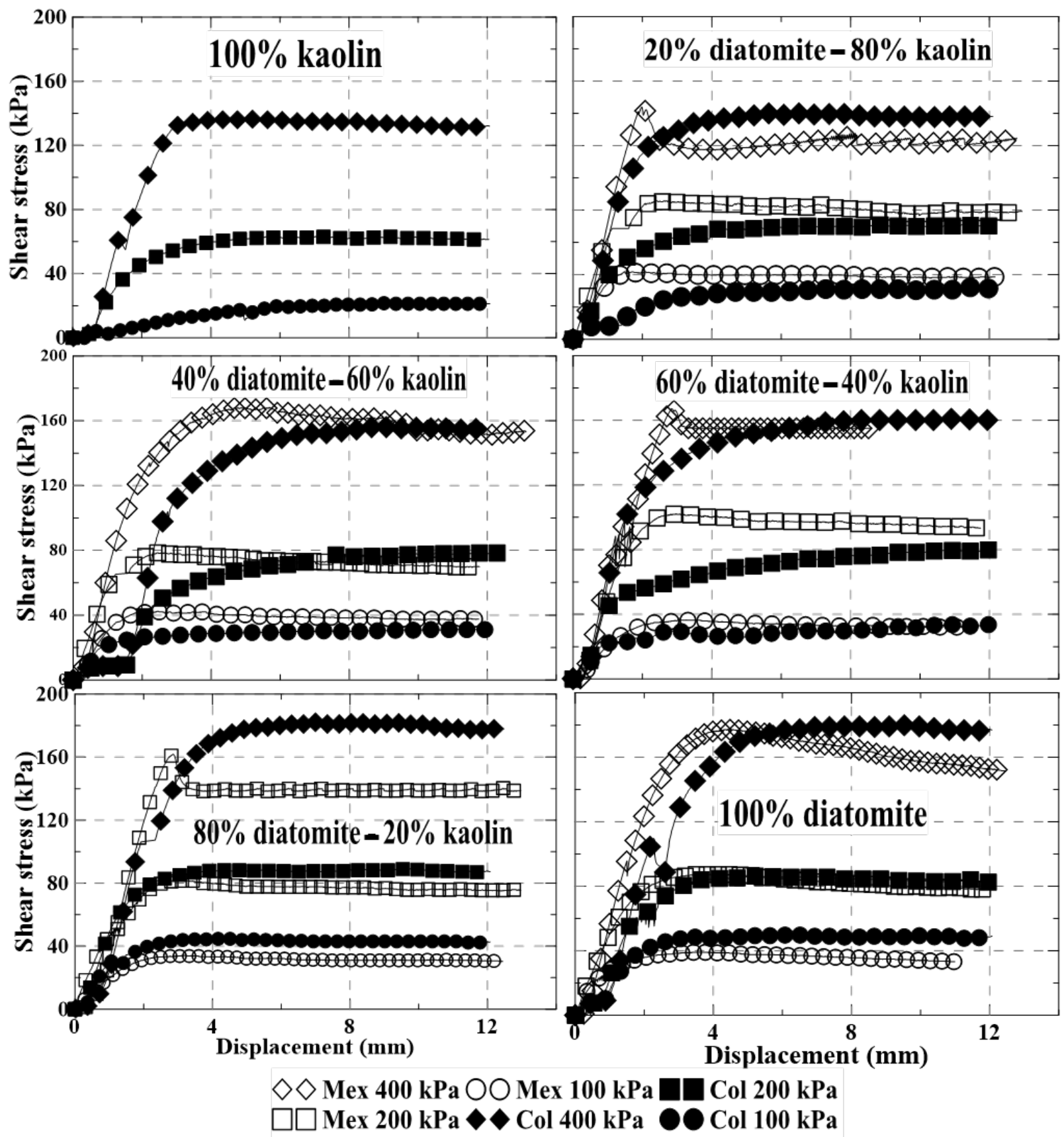

Figure 5. Illustrative example for shear stress vs. displacement curve.

To analyze the volumetric behavior of the diatomite-kaolin mixtures, the vertical displacement was also recorded for all the specimens, as can be observed in Figure 6. From the graphs, two important aspects were deemed for analysis: firstly, the deformability observed in the specimens when they were subjected to different consolidation stresses prior to the torque shear stage and secondly, the behavior observed in the composite material by the influence of diatomite. In the $100 \%$ kaolin mixture, the material presented a contractive behavior during the shear stage being very similar to a normally consolidated clay or, at most, a slightly over-consolidated clay, as was expected. The same phenomenon was displayed until reaching the combination with $40 \%$ diatomite and $60 \%$ kaolin, where the mixture began to reveal a dilatancy response, especially at the highest consolidation stress (i.e., $400 \mathrm{kPa}$ ). The above could be due to the presence of diatomaceous material which provided frictional properties to the specimens. The behavior at $400 \mathrm{kPa}$ was that typically shown by a dense granular material. 

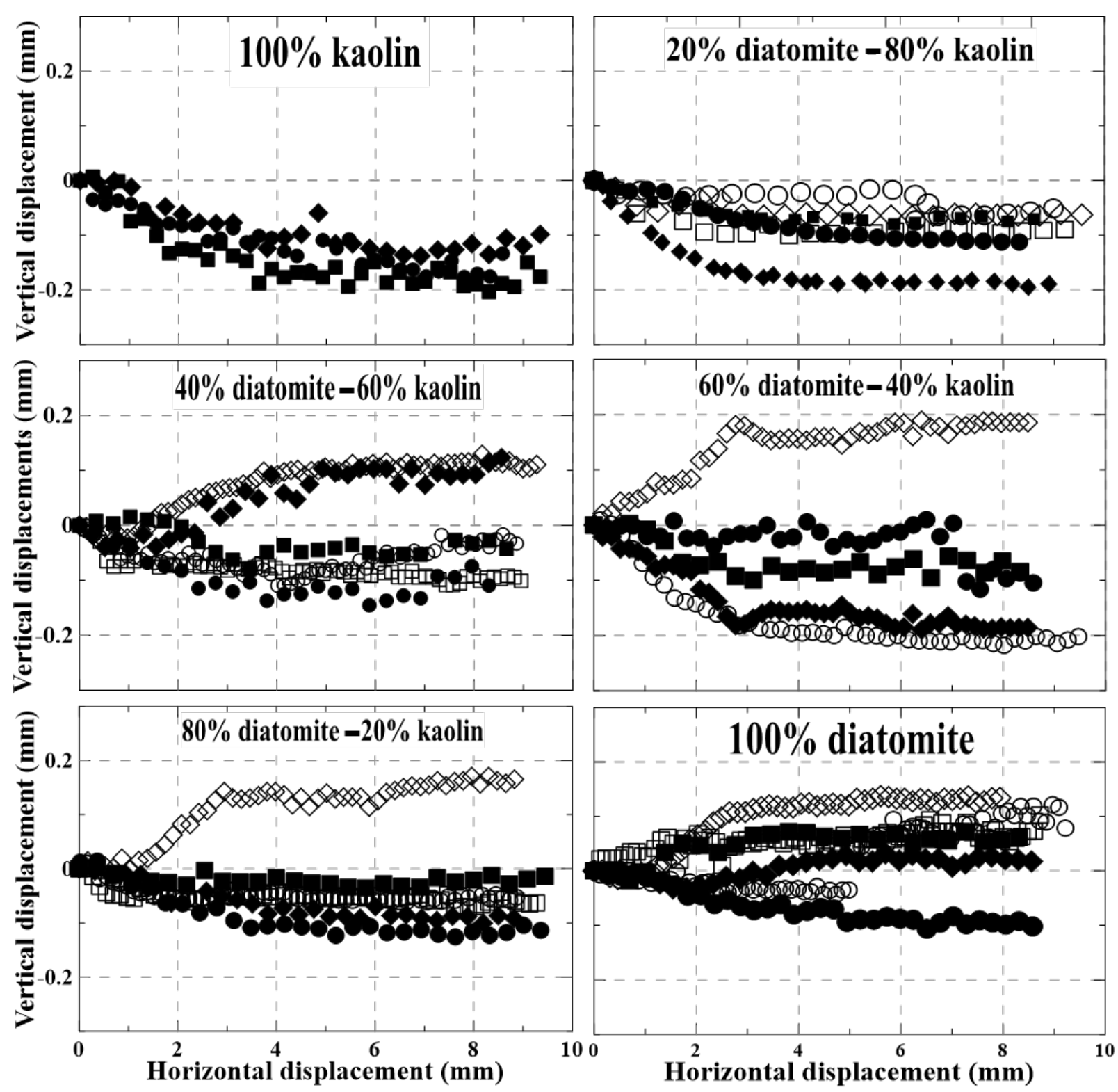

\section{$\diamond \diamond$ Mex $400 \mathrm{kPa} \bigcirc \bigcirc \mathrm{Mex} 100 \mathrm{kPa} \square \mathrm{Col} 200 \mathrm{kPa}$ Mex $200 \mathrm{kPa} \diamond$ Col $400 \mathrm{kPa} \bigcirc \mathrm{Col} 100 \mathrm{kPa}$}

Figure 6. Vertical vs. horizontal displacement for both species analyzed at $60 \%$ diatomite content.

The same phenomenon was more noticeable in the diatomite-kaolin mixtures manufactured with Mexican diatomite content equal to or greater than $40 \%$, where the behavior at stresses of $400 \mathrm{kPa}$ was always revealing dilatancy. This may have been influenced by the microstructural configuration of the Mexican diatomite where the discs present could interlock more easily than the cylinders shown by the Colombian species. This is consistent with what has been found in previous studies [21]. In samples prepared with $100 \%$ diatomite, the dilatancy was also observed at a medium normal stress (e.g., $200 \mathrm{kPa})$ for both species. Therefore, it could be believed that, when the specimen has the presence of only diatomaceous material, the behavior is more similar to a dense or compacted granular material.

Figure 7 reveals the failure envelopes obtained from the annular shear strength test for the peak shear strength resistance for both diatom microfossil species. With respect to the modified mixtures with Colombian diatomite, at low normal stresses, the shear stress 
seemed to be very similar for any content of diatom. Meanwhile, with increasing normal effort, the variability tended to be slightly higher. Regarding mixtures manufactured with Mexican diatomite, more pronounced changes are noted from diatomite contents equal to or above $60 \%$. The trend also indicates that, as the diatom content increased from $60 \%$ to $100 \%$, the shear stress tended to increase, especially at high normal stresses.
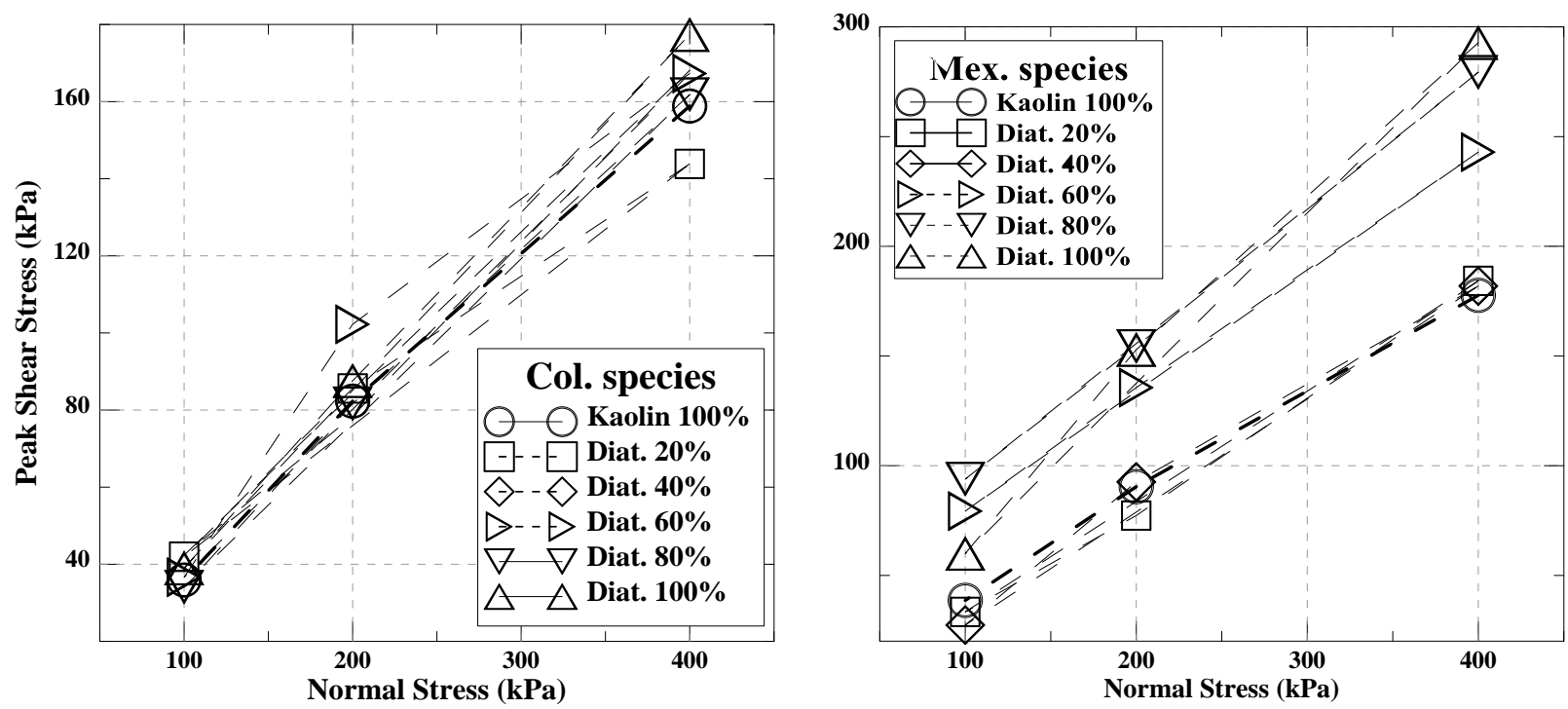

Figure 7. Relationship between peak shear stress vs. normal stress at different diatom contents.

Comparing the results from both diatomite species, the peak shear strength was much higher when modifying the kaolin mixture with Mexican diatomite instead of Colombian diatomite, especially when the confined vertical pressure was higher and with diatom contents superior to $60 \%$. To cite an example, Mexican diatomite $60 \%$ displayed increments of $116 \%, 33 \%$, and $45 \%$ when compared to Colombian diatomite $60 \%$ on peak shear stresses at 100,200 , and $400 \mathrm{kPa}$, respectively. In the same way, Mexican diatomite $80 \%$ showed values of peak shear stress of $93.85,154.36$, and 279.32 while Colombian diatomite $80 \%$ presented values of $34.08,81.64$, and 161.83 at vertical pressures of 100,200 , and $400 \mathrm{kPa}$, respectively. These findings support the notion that the shape and the species of the diatomite influence the peak shear resistance of soil.

Similar to peak shear strength, the residual shear strength for all diatomite-kaolin mixtures was obtained, as can be observed in Figure 8. It was evident that, as the residual shear strength was recorded at large displacements, the values attained would be lower than the peak shear strength. Nonetheless, similar trends were observed. Regarding mixtures modified with Colombian diatomite, at $100 \mathrm{kPa}$ of normal stress, the results were very similar despite the diatom content. However, at large normal stresses, the variance among the mixtures was higher. On the contrary, mixtures with Mexican diatomite showed higher dispersion at $100 \mathrm{kPa}$ and lower variability at $400 \mathrm{kPa}$. Adding Colombian diatomite, no clear improvement in residual shear stress was observed. Mexican diatomite denoted higher values of residual shear strength, especially with diatom contents equal to or higher than $60 \%$, as was observed in the peak shear strength as well. However, this improvement was more noticeable at lower vertical pressures.

From the normal shear stress plots, the peak and the residual friction angles, which are indicators of the effect interlocking between particles and the variation of the friction angle, were calculated for all kaolin-diatomite specimens (see Figure 9). The cohesion for both peak and residual states was nulled in view of the contractive volumetric response, typical for normally consolidated materials. Concerning Colombian diatomite contents, the variation of the friction angle was almost negligible. In fact, as the diatomite content increased, the gap between peak and friction angles became smaller. This result suggests 
that this diatomite leads to an increase in the residual friction angle at a higher rate than the friction angle. On the other hand, the variation of the friction angle was higher as the Mexican diatomite content increased. Although the addition of Mexican diatomite may increase both peak and residual friction angles, the growth rate is greater for the peak rather than the residual one.
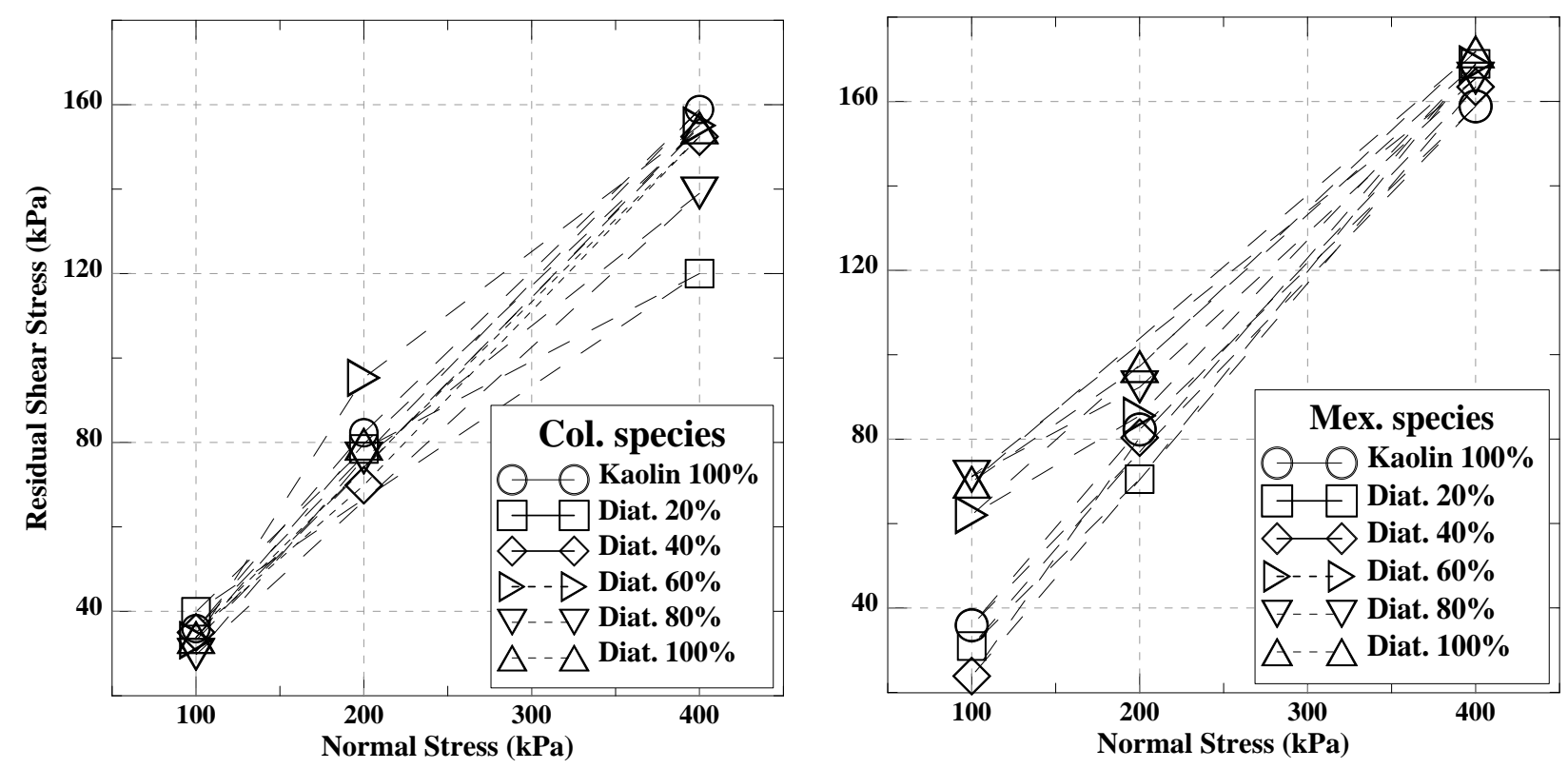

Figure 8. Relationship between residual shear stress vs. normal stress at different diatom contents.

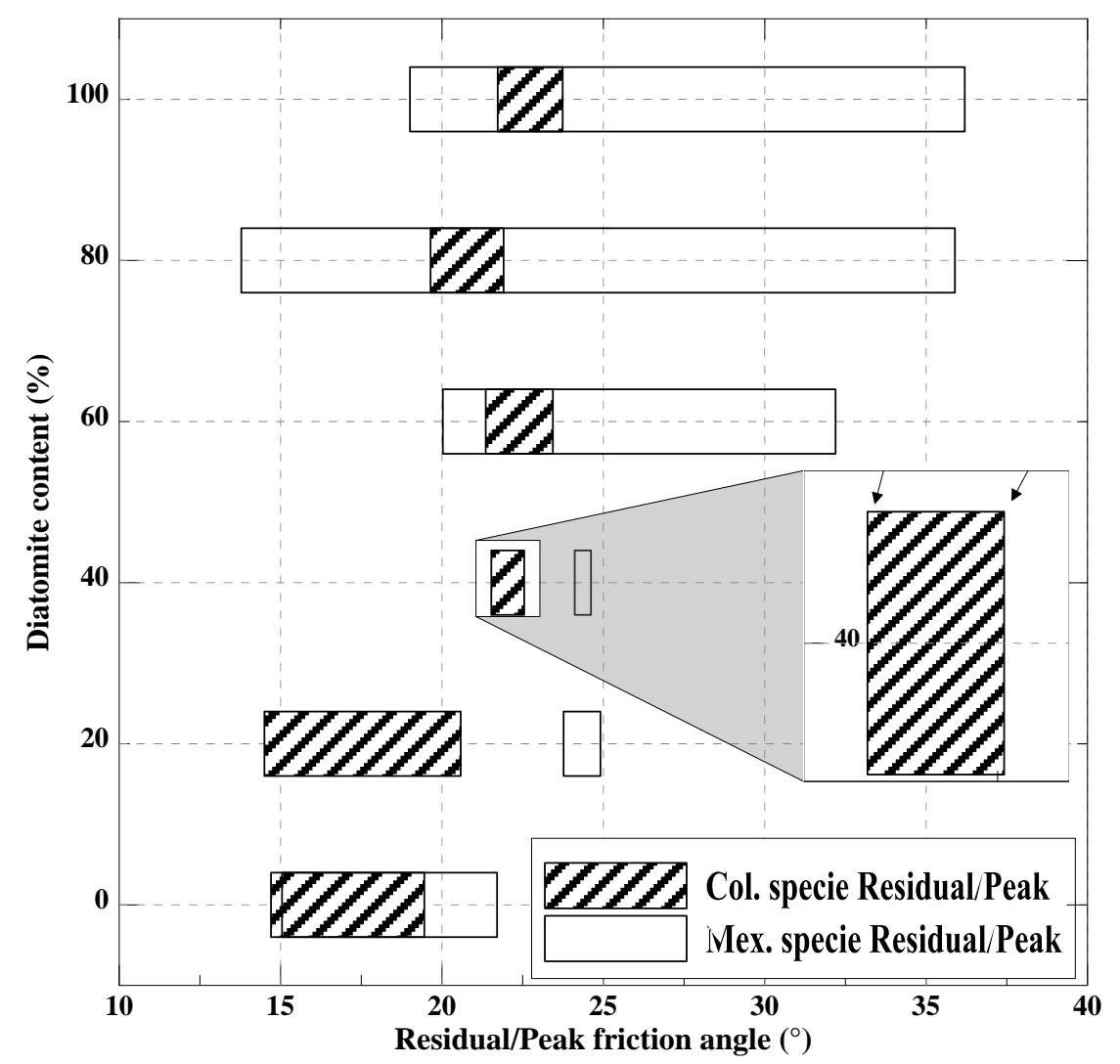

Figure 9. Variation of the effective friction angle respect diatomite content in both species. 
A correlation between peak and residual friction angles was also observed for both types of diatomite, as shown in Figure 10. In the case of mixtures modified with Colombian diatomite, the relationship between the peak and the residual friction angle was positively direct with a $R^{2}$ of 0.88 , whereas in the case of mixtures modified with Mexican diatomite, a good correlation with a $\mathrm{R}^{2}$ value of more than 0.80 was obtained. However, while the residual friction angle tended to increase, the peak angle was getting lower values. From the graph, it can also be inferred that the addition of higher amounts of Colombian diatomite led to an increase in the interlocking effect between particles in short and large deformation levels. Meanwhile, the inclusion of Mexican diatomite also interlocked well with soil particles as its content increased. Nonetheless, at large displacement levels, it tended to dissipate them.

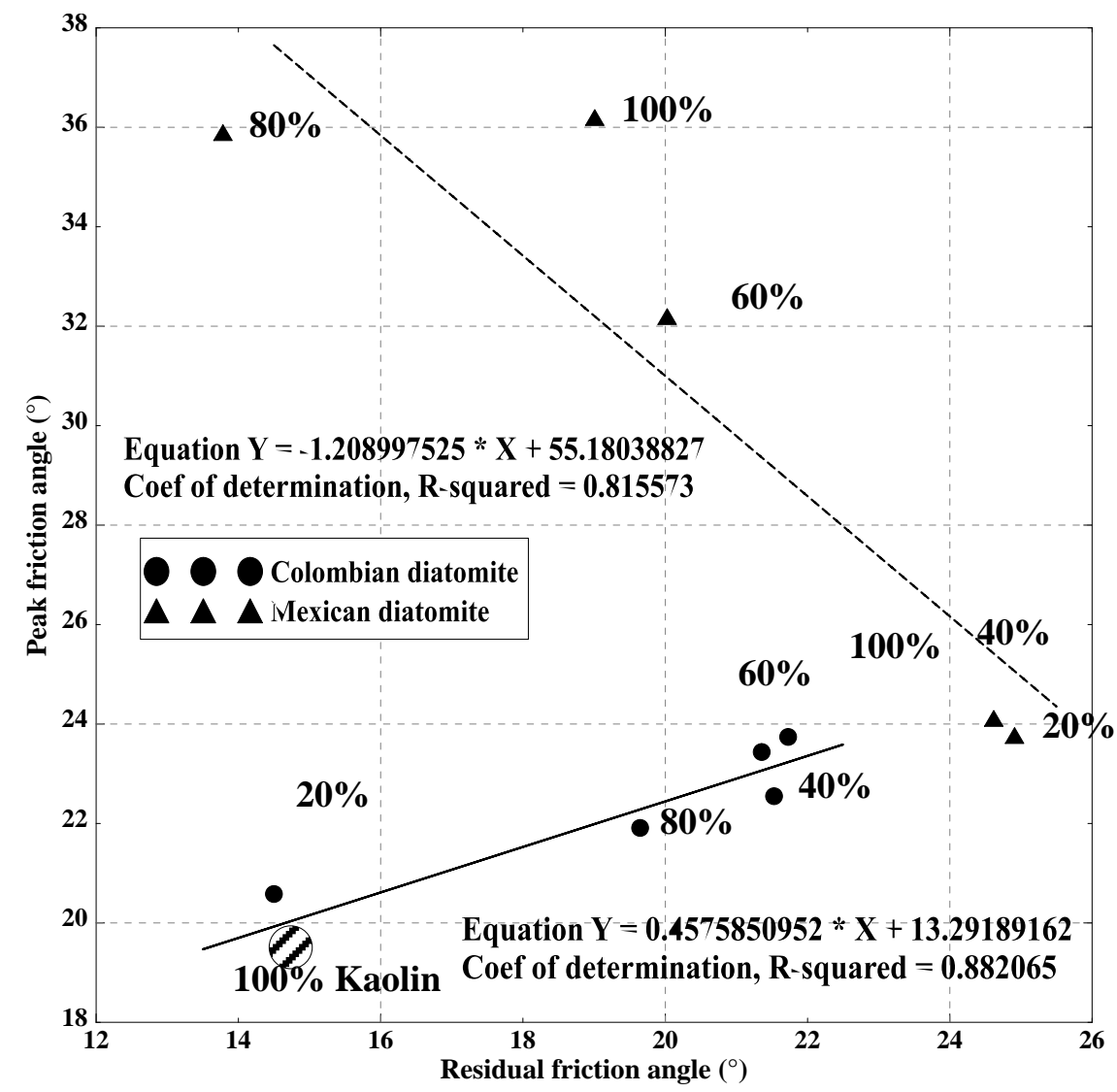

Figure 10. Correlation between peak and residual friction angle.

\section{Conclusions}

In this research, the influence of diatomite species and content in peak and residual shear strength of diatomite-kaolin mixtures was analyzed using the annular shear strength test. Scanning electron microscopy and Atterberg limits were also carried out as additional tests to explain the interlocking effect between the microfossils and the kaolin. Based on the experimental results, the following conclusions are drawn:

- According to SEM images, both diatomite species have larger voids content due to the pores disposed along their surfaces. The presence of these pores can be related to aspects such high water retention that influences the results of tests such as the Atterberg limits. For both species, the higher the diatomite content was, the higher the liquid limit and the plastic limit values were. However, diatomite-kaolin mixtures manufactured with Mexican species displayed greater values, suggesting that this diatomite has larger porosity in its structure.

- For the annular shear strength test, the results show the increment in the peak and the residual strength as the normal stress increased. A linear behavior was observed 
in almost the totality of the mixtures. Comparing the results from both diatomite species, the peak shear strength was much higher when modifying the kaolin mixture with Mexican diatomite instead of Colombian diatomite, especially when the confined vertical pressure was higher and with diatom contents superior to $60 \%$. Regarding residual shear strength, Mexican diatomite also denoted higher values of residual shear strength, especially with diatom contents equal to or higher than $60 \%$ as was observed in the peak shear strength as well.

- The increase of diatomite content in the samples polarized their behavior towards materials similar to compacted sands. Likewise, when the specimens had a higher proportion of clay, their response was contractive, analogous to a normally consolidated clay.

- With respect to the friction angle results, as the diatom content increased, the peak friction angle was also higher. That phenomenon was observed in both species. Nevertheless, the Mexican diatomite revealed higher values compared with Colombian diatomite species. Regarding the residual friction angle, mixtures manufactured with Mexican diatomite also displayed higher values when compared to mixes with Colombian diatomite. In addition, the difference between peak and residual friction angle was higher in Mexican diatomite mixes.

- As has been observed, diatomite has large porosity, low density, and interlocks well with other particles, increasing the shear resistance. Due to these properties, future research is recommended to study the influence of these microfossils in other composites such as concrete or bituminous mixtures.

Author Contributions: Conceptualization, C.J.S.-A., D.A.Z.-A., J.C.R. and D.C.-F.; methodology, C.J.S.-A. and D.A.Z.-A.; formal analysis, C.J.S.-A. and D.A.Z.-A.; resources, C.J.S.-A. D.A.Z.-A. and D.C.-F.; writing-original draft preparation, C.J.S.-A., D.A.Z.-A. and J.C.R.; writing-review and editing, D.C.-F.; funding acquisition, D.A.Z.-A. All authors have read and agreed to the published version of the manuscript.

Funding: This research was funded by Centro de Investigaciones-Escuela de Ingenieros Militares (ESING), budget item A-02-02-02-008-001, Ejército Nacional de Colombia.

Institutional Review Board Statement: Not applicable.

Informed Consent Statement: Not applicable.

Conflicts of Interest: The authors declare no conflict of interest. The funders had no role in the design of the study; in the collection, analyses, or interpretation of data; in the writing of the manuscript, or in the decision to publish the results.

\section{References}

1. Elkateb, T.; Chalaturnyk, R.; Robertson, P.K. An overview of soil heterogeneity: Quantification and implications on geotechnical field problems. Can. Geotech. J. 2003, 40, 1-15. [CrossRef]

2. Matthew Evans, T.; M21111oug, D. Diatomaceous soils: A less than cromulent engineering material. In Geotechnics for Sustainable Infrastructure Development; Springer: Singapore, 2020; pp. 709-716.

3. Ovalle, C.; Arenaldi-Perisic, G. Mechanical behaviour of undisturbed diatomaceous soil. Mar. Georesources Geotechnol. 2020, 1-8. [CrossRef]

4. Montoya-moreno, Y.; Sala, S.; Vouilloud, A.; Aguirre, N. Lista de las diatomeas de ambientes continentales de Colombia. Biota Colomb. 2013, 14, 13-78.

5. Zahajská, P.; Opfergelt, S.; Fritz, S.C.; Stadmark, J.; Conley, D.J. What is diatomite? Quat. Res. 2020, 96, 48-52. [CrossRef]

6. Galvez-Alvarado, J.; Barzola-Gastelú, C.; Gómez-Minaya, R.; Torre-Carrillo, A. Estudio de las diatomitas de ica como materia prima en la fabricación de áridos artificiales de arcilla para su uso como agregados ligeros en mezclas de hormigón diseñados en base a las exigencias de la ntp y astm. Investig. Desarro. 2020, 20, 113-134. [CrossRef]

7. Aksakal, E.L.; Angin, I.; Oztas, T. Effects of diatomite on soil consistency limits and soil compactibility. CATENA 2013, 101, 157-163. [CrossRef]

8. Zhang, Y.; Guo, C.; Yao, X.; Qu, Y.; Zhou, N. Engineering geological characterization of clayey diatomaceous earth deposits encountered in highway projects in the Tengchong region, Yunnan, China. Eng. Geol. 2013, 167, 95-104. [CrossRef]

9. Diaz-Rodriguez, J.A. Diatomaceous soils: Monotonic behavior. Int. Symp. Deform. Charact. Geomaterials 2011, 8. [CrossRef] 
10. Caicedo, B.; Mendoza, C.; López, F.; Lizcano, A. Behavior of diatomaceous soil in lacustrine deposits of Bogotá, Colombia. J. Rock Mech. Geotech. Eng. 2018, 10, 367-379. [CrossRef]

11. Palomino, A.M.; Kim, S.; Summitt, A.; Fratta, D. Impact of diatoms on fabric and chemical stability of diatom-kaolin mixtures. Appl. Clay Sci. 2011, 51, 287-294. [CrossRef]

12. Wiemer, G.; Kopf, A. Influence of diatom microfossils on sediment shear strength and slope stability. Geochem. Geophys. Geosyst. 2017, 18, 333-345. [CrossRef]

13. Arenaldi Perisic, G.; Ovalle, C.; Barrios, A. Compressibility and creep of a diatomaceous soil. Eng. Geol. 2019, $258,105145$. [CrossRef]

14. Shiwakoti, D.; Tanaka, H.; Tanaka, M.; Locat, J. Influences of diatom microfossils on engineering properties of soils. Soils Found. 2002, 43, 1-17. [CrossRef]

15. Ruge, J.C.; Castro-Rincón, W.; Camacho-Tauta, J.; Molina-Gomez, F.A. Dependencia de las Propiedades de Retención de Agua en Suelos Caoliniticos con Contenidos de Microalgas Fosilizadas Adicionadas Artificialmente; IOS Press: Amsterdam, The Netherlands, 2019; pp. 780-787. [CrossRef]

16. Roy, S.; Kumar Bhalla, S. Role of Geotechnical Properties of Soil on Civil Engineering Structures. Resour. Environ. 2017, 7, 103-109.

17. Das, S.K.; Samui, P.; Khan, S.Z.; Sivakugan, N. Machine learning techniques applied to prediction of residual strength of clay. Cent. Eur. J. Geosci. 2011, 3, 449-461. [CrossRef]

18. Schulze, D. Flow Properties of Powders and Bulk Solids. 2014. Available online: https://www.researchgate.net/profile/ Dietmar_Schulze/publication/267818207_Flow_Properties_of_Powders_and_Bulk_Solids/links/5bc59f33458515f7d9bf504d/ Flow-Properties-of-Powders-and-Bulk-Solids.pdf (accessed on 17 November 2020).

19. Mendoza, C.; Muniz de Farias, M. Critical state model for structured soil. J. Rock Mech. Geotech. Eng. 2020, 12, 630-641. [CrossRef]

20. Schofield, A.; Wroth, P. Critical State of Soil Mechanics; McGraw-hill: New York, NY, USA, 1968.

21. Caicedo, B.; Zuluaga, D.; Slebi, C. Effects of micro-features of fossil diatom on the macroscopic behaviour of soils. Géotech. Lett. 2019, 9, 322-327. [CrossRef] 